Onkologie 1993;16(suppl 1):3

\title{
Inhalt - Contents, Vol. 16, Supplement 1, 1993
}

Abstract No. Session Page No.

1. 1-15 Drug Development in Oncology 5

II. 1-12 Early Clinical Trials in Oncology 10

III. 1- 4 Nutrition and the Cancer Patient 16

IV. 1-10 Leukemias and Lymphomas 18

V. 1- 4 Thyroid Cancer 22

VI. 1-12 Urogenital Cancer 23

VII. 1-12 Lung Cancer, Breast Cancer, Melanoma, Gastrointestinal Cancer 28

Author Index 33

Gedruckt mit freundlicher Unterstützung der Glaxo GmbH 